\title{
DYNAMIC CHARACTERISTICS OF WIDE EXPONENTIAL FILM-SHAPE SLIDER BEARINGS LUBRICATED WITH A NONNEWTONIAN COUPLE STRESS FLUID
}

Jaw-Ren Lin

Professor, Department of Mechanical Engineering, Nanya Institute of Technology, P.O. Box 324-22-59, Jhong-li, Taiwan 320., jrlin@nanya.edu.tw

Rong-Fang Lu

Assistant Professor, Department of Mechanical Engineering, Nanya Institute of Technology, P.O. Box 324-22-59,

Jhong-li, Taiwan 320.

Chi-Ren Hung

Instructor, Department of Mechanical Engineering, Nanya Institute of Technology, P.O. Box 324-22-59, Jhong-li, Taiwan 320.

Follow this and additional works at: https://jmstt.ntou.edu.tw/journal

Part of the Mechanical Engineering Commons

\section{Recommended Citation}

Lin, Jaw-Ren; Lu, Rong-Fang; and Hung, Chi-Ren (2006) "DYNAMIC CHARACTERISTICS OF WIDE EXPONENTIAL FILMSHAPE SLIDER BEARINGS LUBRICATED WITH A NONNEWTONIAN COUPLE STRESS FLUID," Journal of Marine Science and Technology: Vol. 14: Iss. 2, Article 4.

DOI: $10.51400 / 2709-6998.2062$

Available at: https://jmstt.ntou.edu.tw/journal/vol14/iss2/4

This Research Article is brought to you for free and open access by Journal of Marine Science and Technology. It has been accepted for inclusion in Journal of Marine Science and Technology by an authorized editor of Journal of Marine Science and Technology. 


\title{
DYNAMIC CHARACTERISTICS OF WIDE EXPONENTIAL FILM-SHAPE SLIDER BEARINGS LUBRICATED WITH A NON- NEWTONIAN COUPLE STRESS FLUID
}

\author{
Jaw-Ren Lin*, Rong-Fang Lu**, and Chi-Ren Hung***
}

Key words: exponential film, sliders, dynamic characteristics, micro-continuum theory, couple stress fluid model.

\section{ABSTRACT}

On the basis of the Stokes micro-continuum theory, the nonNewtonian effects of couple stress fluids upon the dynamic characteristics of wide exponential-shaped slider bearings are presented in this paper. To take into account the couple stress effects arising from a Newtonian lubricant blended with various additives, the nonNewtonian couple-stress dynamic Reynolds-type equation is applied to calculate the bearing dynamics. According to the results obtained, the effects of couple stresses signify a decrease in the friction parameter and the volume flow rate, as well as an increase in the loadcarrying capacity, the dynamic stiffness coefficient and the dynamic damping coefficient for the exponential-shape slider bearing. Comparing with those of the inclined plane bearing, the exponential shaped slider bearing designed at larger profile parameters provides not only smaller required volume flow rates, but also higher loadcarrying capacities and better dynamic stiffness and damping characteristics. These improvements of bearing dynamics are more pronounced with increasing values of the non-Newtonian couple stress parameter.

\section{INTRODUCTION}

Slider bearings are generally used to carry the axial-component load or thrust in a rotating shaft which passes through the casing of a primer. Taking into account various film-shape profiles, lubrication performances have been analyzed by Pinkus and Sternlicht [20], Cameron [5], Hamrock [8], Lin et al. [17] and Lin and Hung [18]. Promoted investigations are presented

Paper Submitted 06/16/05, Accepted 08/29/05. Author for Correspondence: Jaw-Ren Lin. E-mail: jrlin@nanya.edu.tw.

*Professor, Department of Mechanical Engineering, Nanya Institute of Technology, P.O. Box 324-22-59, Jhong-li, Taiwan 320.

**Assistant Professor, Department of Mechanical Engineering, Nanya Institute of Technology, P.O. Box 324-22-59, Jhong-li, Taiwan 320.

***Instructor, Department of Mechanical Engineering, Nanya Institute of Technology, P.O. Box 324-22-59, Jhong-li, Taiwan 320. by considering different operating situations such as the viscosity variation across the film by Qvale and Wiltshire [21], the turbulent flows by King and Taylor [9], the inertia effects by Launder and Leschziner [10], the temperature variation of fluid film by Rodkiewicz and Anar [24] and the thermal effects by Talmage and Carpino [28]. With the development of modern machine elements, the increasing use of a Newtonian lubricant blended with various additives has received great attentions. For example, synthetic oils are applied in the thin-film lubrication. Since the flow behaviors of these kinds of non-Newtonian fluids cannot be described accurately by the classical continuum theory, many micro-continuum theories have been proposed by Ariman and Sylvester [1,2] and Stokes [27]. Amongst them, the Stokes micro-continuum theory [27] is the simplest theory of fluids that allows for the presence of couple stresses, body couples and non-symmetric tensors. This couple stress fluid model is intended to account for the particle-size effects and is important for applications of pumping fluids such as animal bloods, liquid crystals, polymer-thickened oils and complex fluids. In the biomechanical regions, studies of the couple stress effects upon the peristaltic transports and synovial joints have been presented by Shehawey and Mekheimer [25], Srivastava [26] and Lin [11]. In the lubrication fields, investigations concerning with the effects of couple stresses on thin-film bearings have been presented by many authors. Representative studies are: the squeeze-film bearings in parallel plates by Ramanaish [22] and Bujurke and Jayaraman [3] and in sphere-plate system by Lin [14]; the hydrostatic bearings in the steady state by Gupta and Sharma [7] and in the dynamic characteristics by Lin [13]; the rolling bearings by Bujurke and Naduvinami [4] and Das [6]; the journal bearings in the steady state by Lin [12] and Mokhiamer et al. [19] and in the dynamic characteristics by Lin [15]; and the inclined plane slider bearings in the steady state by Ramanaish [23] and in the dy- 
namic characteristics by Lin et al. [16]. According to the results discussed, the effects of couple stresses provide an increase in the load capacity, as well as a reduction in the friction parameter and the squeezing velocity. Thereby, the bearing life is lengthened. As surveyed in the above, dynamic characteristics of inclined plane slider bearings have been analyzed with Newtonian fluids by Lin et al. [16] and with couple stress fluids by Lin et al. [17]. Recently, Lin and Hung [18] investigate the dynamic characteristics of exponential-film slider bearings with a Newtonian lubricant. However, the study of bearing dynamics by the use of couple stress fluids is absent. To provide more information in bearing designing, a further research is motivated.

Based upon the Stokes micro-continuum theory, the dynamic characteristics of a wide exponential-film slider bearing lubricated with couple stress fluids are of interest. The non-Newtonian dynamic Reynolds-type equation is applied to take into account the couple stress effects resulting from a Newtonian fluid blended with various additives. A closed-form solution for the film pressure is derived and thereby applied to predict bearing dynamics including the steady load-carrying capacity, the required volume flow, the friction parameter, the temperature rising, the dynamic stiffness coefficient and the dynamic damping coefficient. Compared to the cases of inclined-plane bearings with a Newtonian fluid [16] and with couple stress fluids [17], bearing characteristics for the exponential-shaped film are discussed and presented with various profile parameters and non-Newtonian couple stress parameters.

\section{ANALYSIS}

Figure 1 shows the physical geometry of a wide

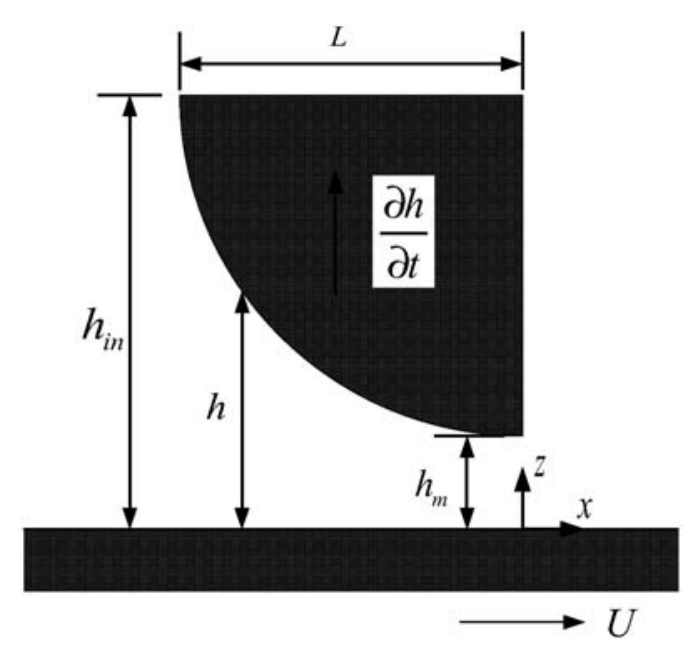

Fig. 1. Physical geometry of a wide slider bearing with an exponential film profile. exponential-film slider bearing of length $L$ with a sliding velocity $U$ and a squeezing velocity $\partial h / \partial t$ in the $x$ direction and the $z$-direction respectively, where $t$ is the time and $h(x, t)$ denotes the film thickness described by:

$$
h(x, t)=h_{m}(t) \cdot \exp \left(-\frac{x}{L} \ln r\right)
$$

In the equation $h_{m}(t)$ is the minimum film thickness at the outlet and $r$ denotes the inlet-outlet film ratio $r=h_{i n}(t) / h_{m}(t)=\left[d+h_{m}(t)\right] / h_{m}(t)$, where $d$ is the shoulder height denoting the difference between inlet height and outlet height. The lubricant in the film region is taken to be an incompressible Stokes couple stress fluid. Based upon the thin-film theory of hydrodynamic lubrication, the non-Newtonian couple-stress dynamic Reynolds-type equation for a wide slider bearing is derived from [17].

$$
\begin{aligned}
& \frac{d}{d x}\left[f(h, l) \frac{d p}{d x}\right]=6 \mu U \frac{\partial h}{\partial x}+12 \mu \frac{\partial h}{\partial x} \\
& f(h, l)=h^{3}-12 l^{2}\left[h-2 l \tanh \left(\frac{h}{2 l}\right)\right]
\end{aligned}
$$

where $\mu$ is the shear viscosity, and $l=(\eta / \mu)^{1 / 2}$ is identified as the molecular length of the polar suspensions in a non-polar fluid, in which $\eta$ denotes a new material constant responsible for the couple stress fluid. Introduce the dimensionless variables and parameters defined as follows.

$$
\begin{aligned}
& x^{*}=\frac{x}{L}, t^{*}=\frac{U t}{L}, h_{m}^{*}=\frac{h_{m}}{h_{m s}}, h^{*}=\frac{h}{h_{m s}} \\
& f^{*}=\frac{f}{h_{m s}^{3}}, p^{*}=\frac{p h_{m s}^{2}}{\mu U L}, l^{*}=\frac{l}{h_{m s}}, \delta^{*}=\frac{d}{h_{m s}}
\end{aligned}
$$

In these equations $h_{m s}$ denotes the steady-state minimum film height, $\delta$ represents the dimensionless profile parameter, and $l^{*}$ represents the dimensionless couple stress parameter accounting for the nonNewtonian couple stress effects. As a consequence, one can obtain the dimensionless non-Newtonian couplestress dynamic Reynolds-type equation.

$$
\begin{aligned}
& \frac{\partial}{\partial x^{*}}\left[f^{*}\left(h^{*}, l^{*}\right) \frac{\partial p^{*}}{\partial x^{*}}\right]=6 \frac{\partial h^{*}}{\partial x^{*}}+12 \frac{\partial h^{*}}{\partial t} \\
& f^{*}\left(h^{*}, l^{*}\right)=h^{* 3}-12 l^{* 2}\left[h^{*}-2 l^{*} \tanh \left(\frac{h^{*}}{2 l^{*}}\right)\right]
\end{aligned}
$$

When the value of $l^{*}$ tends to be zero, the effects of couple stresses vanish, and the non-dimensional nonNewtonian couple-stress dynamic Reynolds-type equa- 
tion reduces to the case of bearings with a Newtonian lubricant by Lin and Hung [18]. Since the linear dynamic characteristics can be obtained for the bearing under small disturbances about its steady state, the inlet-outlet film ratio can be approximated by $r \cong \delta+1$, and the film thickness is then expressed as:

$$
h^{*}\left(x^{*}, t^{*}\right) \cong h_{m}^{*}\left(t^{*}\right) \cdot h_{e}^{*}\left(x^{*}\right)=h_{m}^{*}\left(t^{*}\right) \cdot \exp \left[-x^{*} \ln (d+1)\right]
$$

Integrating the non-dimensional non-Newtonian couple-stress dynamic Reynolds-type equation once with respect to $x^{*}$ gives

$$
\begin{aligned}
\frac{\partial p^{*}}{\partial x^{*}} & =\left[6 h_{m}^{*}-\frac{12}{\ln (\delta+1)} V^{*}\right] \frac{h_{e}^{*}\left(x^{*}\right)}{f^{*}\left(h^{*}, l^{*}\right)} \\
& +c_{1}\left(h_{m}^{*}, V^{*}\right) \frac{1}{f^{*}\left(h^{*}, l^{*}\right)}
\end{aligned}
$$

where $c_{1}\left(h_{m}^{*}, V^{*}\right)$ is the integration function and $V^{*}=d h_{m}^{*} /$ $d t^{*}$ is the squeezing velocity. Integrating again with the zero-pressure conditions at the outlet results in the hydrodynamic film pressure.

$$
\begin{gathered}
p^{*}=\left[6 h_{m}^{*}-\frac{12}{\ln (\delta+1)} V^{*}\right] f_{A}\left(x^{*}, h_{m}^{*}\right) \\
+c_{1}\left(h_{m}^{*}, V^{*}\right) f_{C}\left(x^{*}, h_{m}^{*}\right) \\
f_{A}\left(x^{*}, h_{m}^{*}\right)=\int_{0}^{x^{0}} \frac{h_{e}^{*}\left(x^{*}\right)}{f^{*}\left(h^{*}, x^{*}\right)} d x^{*} \\
f_{C}\left(x^{*}, h_{m}^{*}\right)=\int_{0}^{x 0} \frac{1}{f^{*}\left(h^{*}, x^{*}\right)} d x^{*}
\end{gathered}
$$

The integration function is obtained from the zeropressure condition at the inlet.

$$
\begin{aligned}
& c_{1}=-\left[6 h_{m}^{*}-\frac{12}{\ln (\delta+1)} V^{*}\right] \frac{g_{A}\left(h_{m}^{*}\right)}{g_{C}\left(h_{m}^{*}\right)} \\
& g_{A}\left(h_{m}^{*}\right)=f_{A}\left(x^{*}=-1, h_{m}^{*}\right) \\
& g_{C}\left(h_{m}^{*}\right)=f_{C}\left(x^{*}=-1, h_{m}^{*}\right)
\end{aligned}
$$

The dimensionless hydrodynamic film force is computed by integrating the film pressure over the film region.

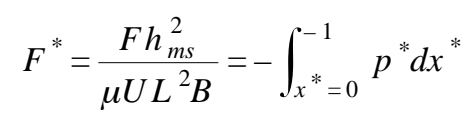

where $B$ denotes the width of the bearing. Performing the integration results in

$$
\begin{gathered}
F^{*}\left(h_{m}^{*}, V^{*}\right)=-\left[6 h_{m}^{*}-\frac{12}{\ln (\delta+1)} V^{*}\right] F_{A}\left(h_{m}^{*}\right) \\
-c_{1}\left(h_{m}^{*}, V^{*}\right) F_{C}\left(h_{m}^{*}\right) \\
F_{A}\left(h_{m}^{*}\right)=\int_{x}^{*}=0 \\
F_{C}\left(h_{m}^{*}\right)=\int_{x}^{*}=0 \\
\left.\int_{C}^{* 1}\left(x^{*}, h_{m}^{*}\right) d x^{*}, h_{m}^{*}\right) d x^{*}
\end{gathered}
$$

\section{BEARING DYNAMICS}

With the hydrodynamic film force known, the steady-state solution can be evaluated by letting the squeezing velocity be zero: $V^{*}=0$. The steady loadcarrying capacity expressed in a dimensionless form is given by:

$$
W_{s}^{*}=F^{*}\left(\left(h_{m}^{*}\right)_{s}, 0\right)=-6\left(h_{m}^{*}\right)_{s}\left(F_{A}\right)_{s}-\left(c_{1}\right)_{s}\left(F_{C}\right)_{s}
$$

where the subscript $s$ denotes the steady-state condition. The steady shear force acting upon the lower part is obtained by integrating shearing stress over the sliding surface. Using the derivation of the shearing stress given by Stokes [27] gives

$$
F_{L s}=\left\{-\int_{x=0}^{-L}\left\{\mu\left[\frac{\partial u}{\partial z}\right]_{Z=0}-\eta\left[\frac{\partial^{3} u}{\partial z^{3}}\right]_{Z=0} B d x\right\}_{s}\right.
$$

Using the velocity distribution obtained by Lin et al. [17], the dimensionless steady shearing force acting upon the sliding surfaces is obtained.

$$
\begin{aligned}
F_{L s}^{*} & =\frac{F_{L s} h_{m s}}{\mu U L B}=-\frac{\delta}{\left(h_{m}^{*}\right)_{s}(\delta+1) \ln (\delta+1)} \\
& +\int_{0}^{-1} \frac{3\left(h^{*}\right)_{s}+2\left(c_{1}\right)_{s}}{2\left(f^{*}\right)_{s}}\left(h^{*}\right)_{s} d x^{*}
\end{aligned}
$$

The friction coefficient can be evaluated by $-F_{L s} /$ $W$. The friction parameter is then obtained.

$$
\mu_{f}=\frac{-F_{L s}}{W_{s}} \cdot \frac{L}{h_{m s}}=\frac{-F_{L s}^{*}}{W_{s}^{*}}
$$

The non-dimensional steady volume flow rate in the $x$ direction is defined as: 


$$
Q_{s}^{*}=\frac{q_{x}}{U h_{m s} B}=\left(\int_{z^{*}=0}^{h^{*}} u^{*} d z^{*}\right)_{s}
$$

Let $x_{M}^{*}$ denote the position where the steady maximum pressure occurs. Evaluating the flow rate where $d p^{*} / d x^{*}=0$ gives

$$
Q_{s}^{*}=\left(\left[\frac{1}{2} h^{*}\right]_{x^{*}=x_{M}^{*}}\right)_{s}
$$

The temperature rising owing the work done against the shearing stresses may be transferred by convection, conduction or radiation. The bulk heat flow is carried by the convection of the lubricant. Following the procedure by Hamrock [8], the steady temperature rising $t_{m}$ expressed in a dimensionless form is obtained.

$$
t_{m}^{*}=\frac{J C_{p} \rho g h_{m s}^{2}}{\mu U L} t_{m}=-\frac{F_{L s}^{*}}{Q_{s}}
$$

Both the linear dynamic stiffness coefficient and the linear dynamic damping coefficient can be calculated by taking the derivative of hydrodynamic film force with respect to the film height and the squeezing velocity, respectively.

$$
\begin{aligned}
& S_{s}^{*}=\frac{S_{c} h_{m s}^{2}}{\mu U L^{2} B}=-\left(\frac{\partial F^{*}}{\partial h_{m}^{*}}\right)_{s} \\
& D_{c}^{*}=\frac{D_{c} h_{m s}^{3}}{\mu L^{3} B}=-\left(\frac{\partial F^{*}}{\partial V^{*}}\right)_{s}
\end{aligned}
$$

Using the expression of $F^{*}$ and performing the derivatives, on can obtain the dynamic stiffness coefficient and the dynamic damping coefficient, respectively.

$$
\begin{aligned}
S_{c}^{*} & =6\left(F_{A}\right)_{s}+6\left(h_{m}^{*}\right)_{s}\left(\frac{\partial F_{A}}{\partial h_{m}^{*}}\right)_{s}+\left(\frac{\partial c_{1}}{\partial h_{m}^{*}}\right)_{s}\left(F_{C}\right)_{s} \\
& +\left(c_{1}\right)_{s}\left(\frac{\partial F_{C}}{\partial h_{m}^{*}}\right)_{s} \\
D_{c}^{*} & =-\frac{12}{\ln (\delta+1)}\left(F_{A}\right)_{s}+\left(\frac{\partial c_{1}}{\partial V^{*}}\right)_{s}\left(F_{C}\right)_{s}
\end{aligned}
$$

where

$$
\begin{aligned}
& \left(\frac{\partial F_{A}}{\partial h_{m}^{*}}\right)_{s}=\left[\int_{0}^{-1} \int_{0}^{x^{*}} \frac{-h_{e}^{*}}{f^{* 2}} \frac{\partial f^{*}}{\partial h_{m}^{*}} d x^{*} d x^{*}\right]_{s} \\
& \left(\frac{\partial F_{C}}{\partial h_{m}^{*}}\right)_{s}=\left[\int_{0}^{-1} \int_{0}^{x^{*}} \frac{-1}{f^{* 2}} \frac{\partial f^{*}}{\partial h_{m}^{*}} d x^{*} d x^{*}\right]_{s}
\end{aligned}
$$

$$
\begin{aligned}
& \left(\frac{\partial c_{1}}{\partial h_{m}^{*}}\right)_{s}=\left\{\frac{-6}{g_{A}^{2}}\left[g_{C}\left(g_{A}+h_{m}^{*} \frac{\partial g_{A}}{\partial h_{m}^{*}}\right)-g_{A}\left(g_{C}+h_{m}^{*} \frac{\partial g_{C}}{\partial h_{m}^{*}}\right)\right]\right\}_{s} \\
& \left(\frac{\partial c_{1}}{\partial V^{*}}\right)_{s}=\frac{12}{\ln (\delta+1)} \frac{\left(g_{A}\right)_{s}}{\left(g_{C}\right)_{s}}
\end{aligned}
$$

\section{RESULTS AND DISCUSSION}

Since the dimension of $l=(\eta / \mu)^{1 / 2}$ is of length, it may be considered as the characteristic material length or the molecular length of the suspended particles in a nonpolar fluid. Thus the value of $l$ will vary in different lubricants. With the aid of the dimensionless parameter defined by $l^{*}=l / h_{m s}$, the effects of couple stresses due to the lubricant containing additives or suspended particles upon the bearing performances are characterized by this couple stress parameter as the steady-state minimum film height $h_{m s}$ is fixed. Since the value of $\eta$ could be determined by some experiments as discussed by Stokes [27] and the use of additives is a small amount, the value of $l^{*}$ is expected to be not large. In the present study, bearing dynamics are presented with couple stress parameter within the range of $l^{*}=0 \sim 0.5$.

Figure 2 presents the variation of dimensionless steady load-carrying capacity $W_{s}^{*}$ with profile parameter $\delta$ for different values of the couple stress parameter $l^{*}$. Bearing load capacities are observed to increase with

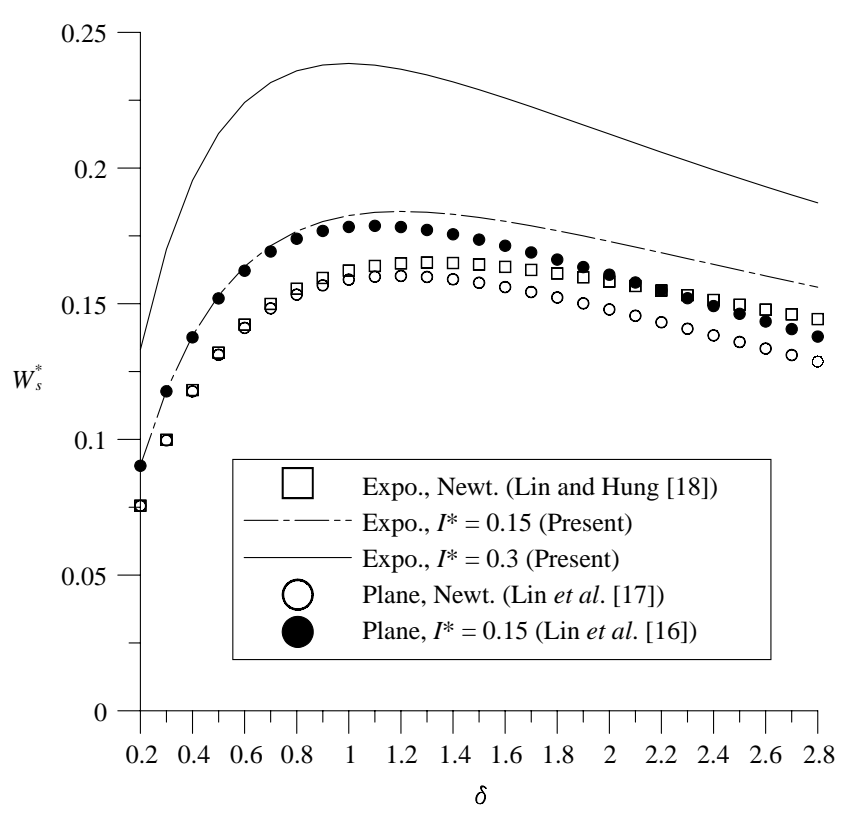

Fig. 2. Variation of steady load-carrying capacity $W_{s}^{*}$ with profile parameter $\delta$ for different couple stress parameters $l$. 
until a critical value is reached, and thereafter falls as the profile parameter continues to increase. Comparing with the Newtonian-lubricant case of an exponentialfilm slider by Lin and Hung [18], the effects of couple stresses $\left(l^{*}=0.15\right.$ and $\left.l^{*}=0.3\right)$ for the present analysis provide an enhancement in the load-carrying capacity. Comparing with those of the inclined plane sliders with a Newtonian fluid by Lin et al. [16] and with a couple stress fluid $\left(l^{*}=0.15\right)$ by Lin et al. [18], the bearing geometry of the exponential-film slider results in a higher load-carrying capacity for larger values of the profile parameter. Figure 3 shows the variation of friction parameter $\mu_{f}$ with $\delta$ for different values of $l^{*}$. The friction parameter decreases with the profile parameter to reach a minimum, and thereafter increases with the profile parameter. Comparing with the Newtonian-lubricant case, the effects of couple stresses $\left(l^{*}=0.15\right)$ provide a reduction in the friction parameter for both types of bearings. Further reductions are emphasized for a larger couple stress parameter $\left(l^{*}=0\right.$. 3 ) of the exponential-film bearing. However, the effects of bearing geometry (inclined-plane vs. exponential-shape) upon the friction parameter are observed to be slight for the bearings with a Newtonian fluid and with a couple stress fluid $\left(l^{*}=0.15\right)$. Figure 4 describes the variation of adiabatic temperature rise with profile parameter $t_{m}^{*}$ for different $l^{*}$. For both types of bearings the temperature rise is observed to decrease with increasing the profile parameter. Comparing with the Newtonian-lubricant case of the exponential-film slider, the effects of couple stresses $\left(l^{*}=0.15\right.$ and $\left.l^{*}=0.3\right)$ yield

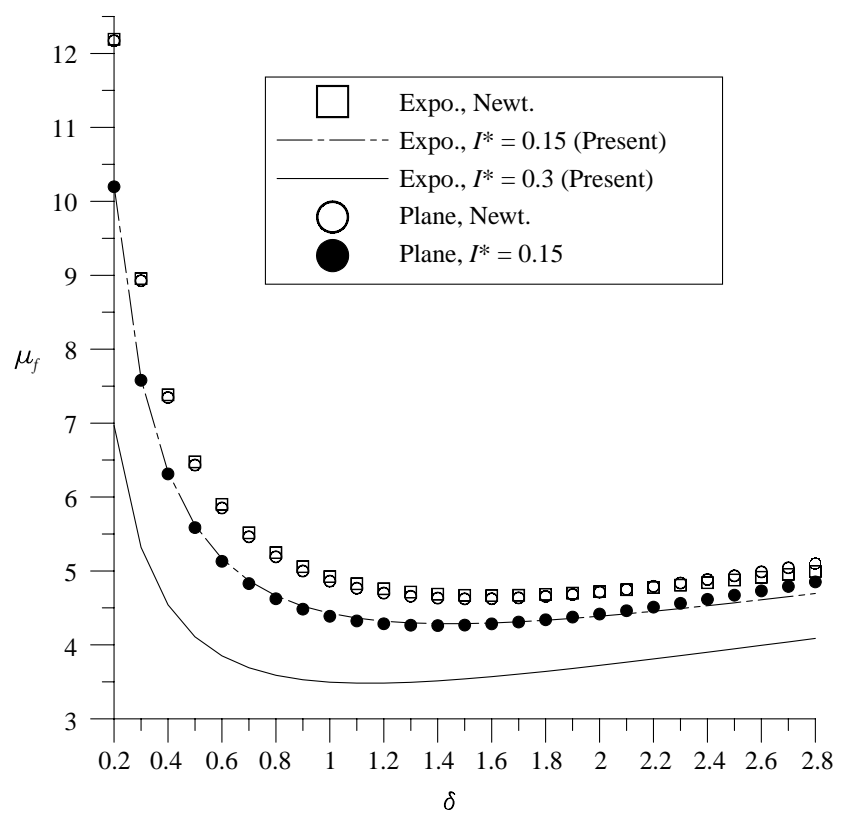

Fig. 3. Variation of friction parameter $\mu_{f}$ with profile parameter $\delta$ for different couple stress parameters $l^{*}$. higher temperature rises. Comparing with those of the inclined plane sliders with a Newtonian fluid and with a couple stress fluid $\left(l^{*}=0.15\right)$, the exponential-film bearing results in higher values of the temperature rising. These phenomena can be realized from Figure 5, in which the variation of volume flow rate $Q_{s}^{*}$ with profile parameter $\delta$ for different $l^{*}=0.15$ is displayed.

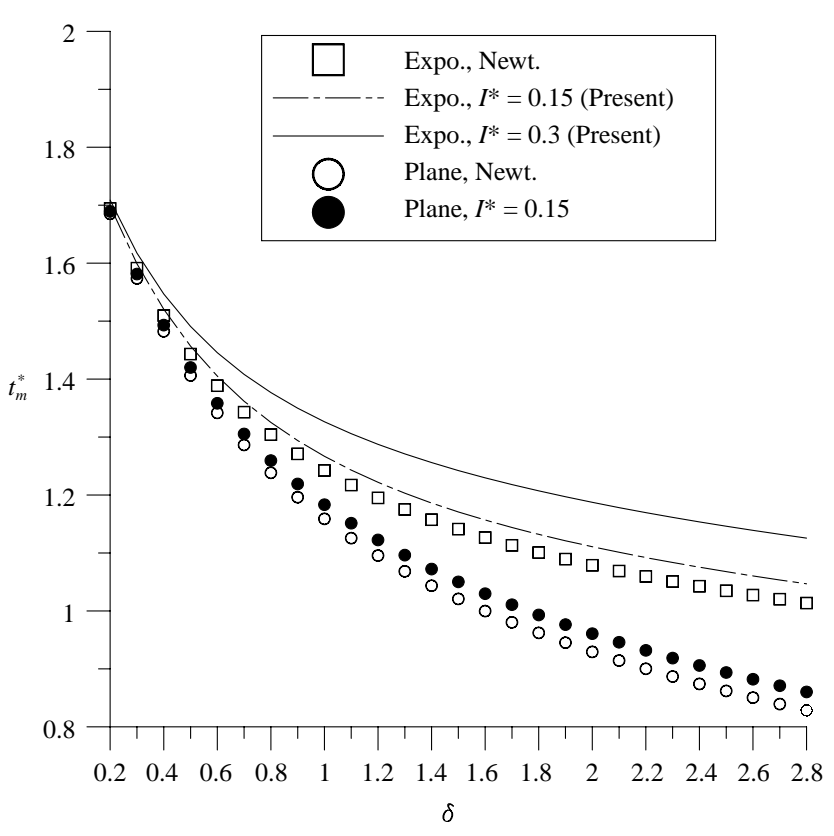

Fig. 4. Variation of temperature rising $t_{m}^{*}$ with profile parameter $\delta$ for different couple stress parameters $l^{*}$.

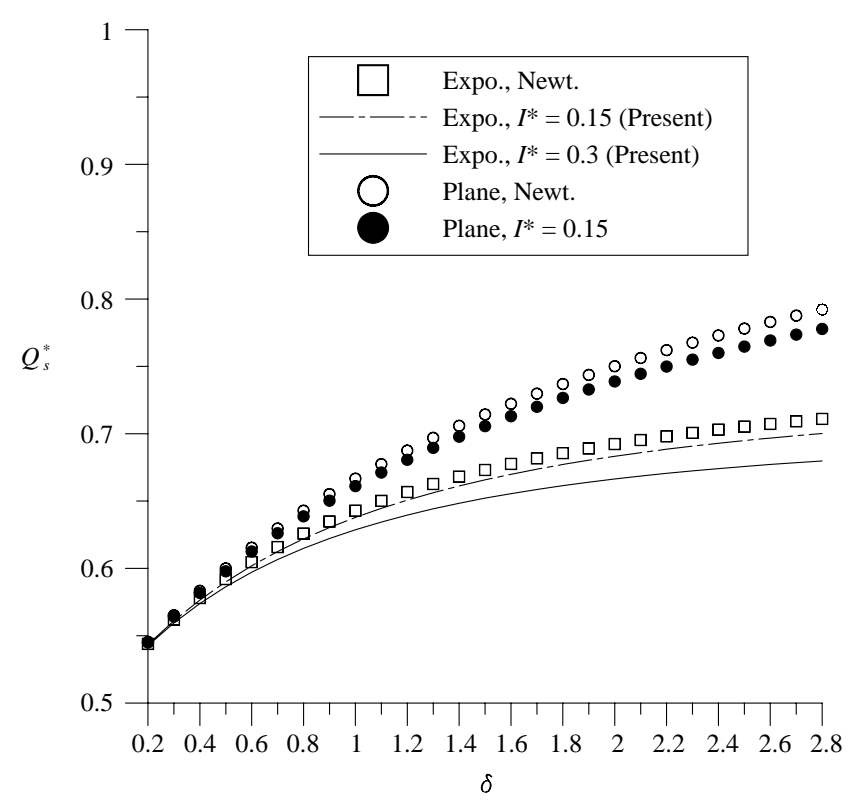

Fig. 5. Variation of volume flow rate $Q_{s}^{*}$ with profile parameter $\delta$ for different couple stress parameters $l^{*}$. 
The presence of couple stresses is observed to decrease the required volume flow rate. Therefore the effects of couple stresses increase the temperature rise. In addition, the exponential-film bearings require a smaller amount of the required flow rate, therefore higher temperature rises are achieved as compared to the inclined plane bearings.

Figure 6 presents the variation of dimensionless dynamic stiffness coefficient $S_{c}^{*}$ with profile parameter for different values of $l^{*}$. Similar to the tendency of bearing loads, the stiffness coefficient increases with profile parameter until a critical value is obtained, and thereafter falls as the profile parameter continues to increase. Comparing with the Newtonian-lubricant case of the exponential-film slider, the couple stress effects $\left(l^{*}=0.15\right.$ and $\left.l^{*}=0.3\right)$ are observed to increase the bearing stiffness. Comparing with those of the inclined plane bearings with a Newtonian fluid and with a couple stress fluid $\left(l^{*}=0.15\right)$, the exponential-film slider results in a significantly increased stiffness for larger values of the profile parameter. Figure 7 shows the variation of dimensionless dynamic damping coefficient $D_{c}^{*}$ with profile parameter $\delta$ for different $l^{*}$. For both types of bearings, increasing values of the profile parameter yields a decreasing damping coefficient. However, the effects of couple stresses are observed to increase the value of damping coefficients. Comparing with those of the inclined plane sliders, the exponentialfilm bearings provide a higher damping coefficient, especially for larger values of the profile parameter.

Observing the results obtained in Figures 2 7, the

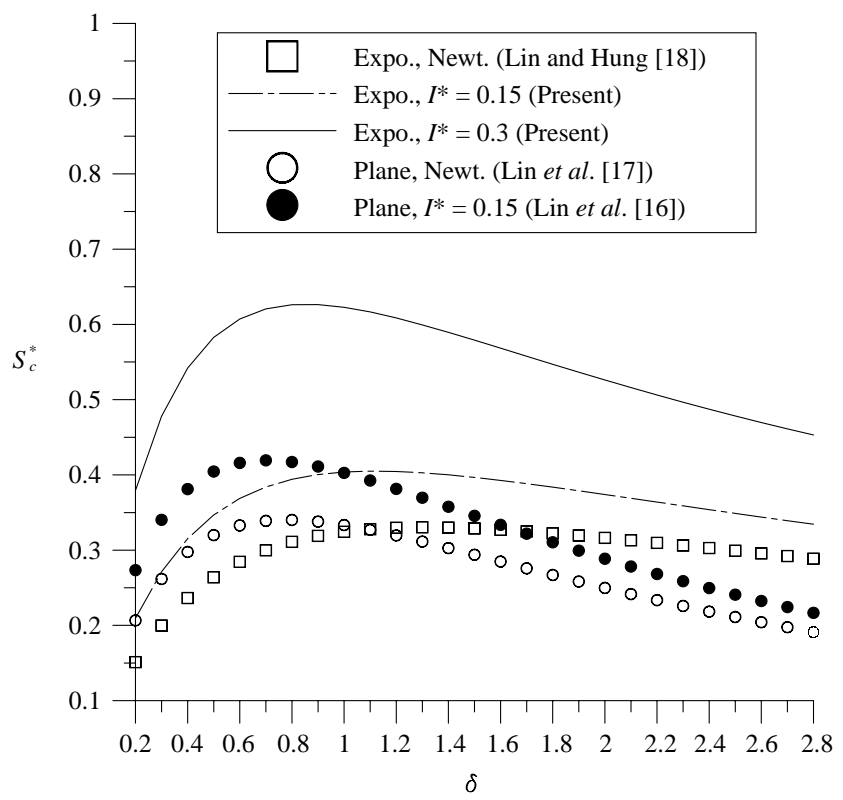

Fig. 6. Variation of stiffness coefficient $S_{c}^{*}$ with profile parameter $\delta$ for different couple stress parameters $l^{*}$. effects of couple stresses increase the load-carrying capacity, the temperature rising, the stiffness coefficient and the damping coefficient; and decrease the friction parameter and the volume flow rate for both types of the bearings. However, the bearing geometry (inclined-plane vs. exponential-shape) with smaller profile parameters has slight effects on the load-carrying capacity, the friction parameter, the temperature rising and the volume flow rate. In addition, the exponentialshape slider results in a smaller stiffness coefficient as compared to the inclined-plane slider designed at a small profile parameter. To provide more information for engineering applications, a comparison of bearing characteristics between the exponential-shape slider and the inclined-plane slider lubricated with couple stress fluids designed at larger profile parameters are presented in Figure 8 and Figure 9. The effects of couple stresses are observed to reduce the friction parameter and the volume flow rate, as well as increase the load-carrying capacity, the stiffness coefficient and the damping coefficient. Comparing with those of the inclined plane sliders, the exponential shaped slider with a larger profile parameter $(\delta=2.4)$ provides a higher load-carrying capacity, a lower friction parameter, a smaller required volume flow rate, a higher stiffness coefficient and a higher damping coefficient. Totally, larger values of the profile parameter for the exponential shaped slider provides smaller friction parameters and required volume flow rates, higher load-carrying capacities and better dynamic stiffness and damping characteristics as compared to those of the inclined

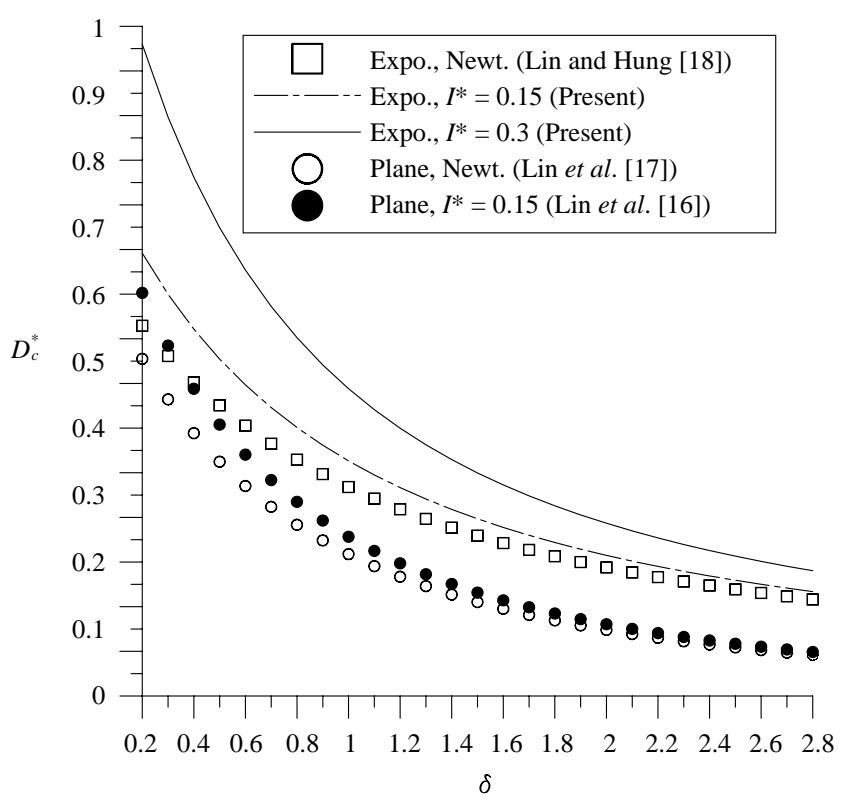

Fig. 7. Variation of damping coefficient $D_{c}^{*}$ with profile parameter $\delta$ for different couple stress parameters $l^{*}$. 
slider bearings. These improvements of bearing dynamics are more pronounced with increasing values of the non-Newtonian couple stress parameter.

To illustrate the use of the study, consider the following data: $h_{m s}=2.0 \times 10^{-4} \mathrm{~m}, d=\delta \cdot h_{m s}=(2.4)$. $h_{m s}, \mu=1.0 \times 10^{-2} \mathrm{~Pa} \cdot \mathrm{s}, \eta=(0 \sim 1) \times 10^{-10} \mathrm{~N} \cdot \mathrm{s}$. Then the profile parameter and the couple stress parameter are obtained: $\delta=2.4, l^{*}=0 \sim 0.5$. From Eqs. $(15,17,19$, 21-23) using $\left(h_{m}^{*}\right)_{s}=1$ and $\left(V^{*}\right)_{s}=0$, the steady-state performance and the dynamic characteristics of the exponential-film slider bearing have been presented in Figures 8 and 9.

It is worthy to note that the definition of $\delta$ represents the ratio of the shoulder height $d$ to the steadystate minimum film height $h_{m s}$. For practical application the height of $h_{m s}$ is small as compared to the value $d$, and therefore the range of the variation of $\delta$ may be large. According the results obtained and discussed, the present study is confined within the range of $\delta=0.2 \sim$ 2.8. Further analyses will be presented in the future study.

\section{CONCLUSION}

On the basis of the Stokes micro-continuum theory, the study of dynamic characteristics of a wide exponential-film slider bearing lubricated with couple stress fluids is presented. To take into account the couple stress effects resulting from a Newtonian lubricant blended with various additives, the hydrodynamic film pressure is solved from the non-Newtonian couple-

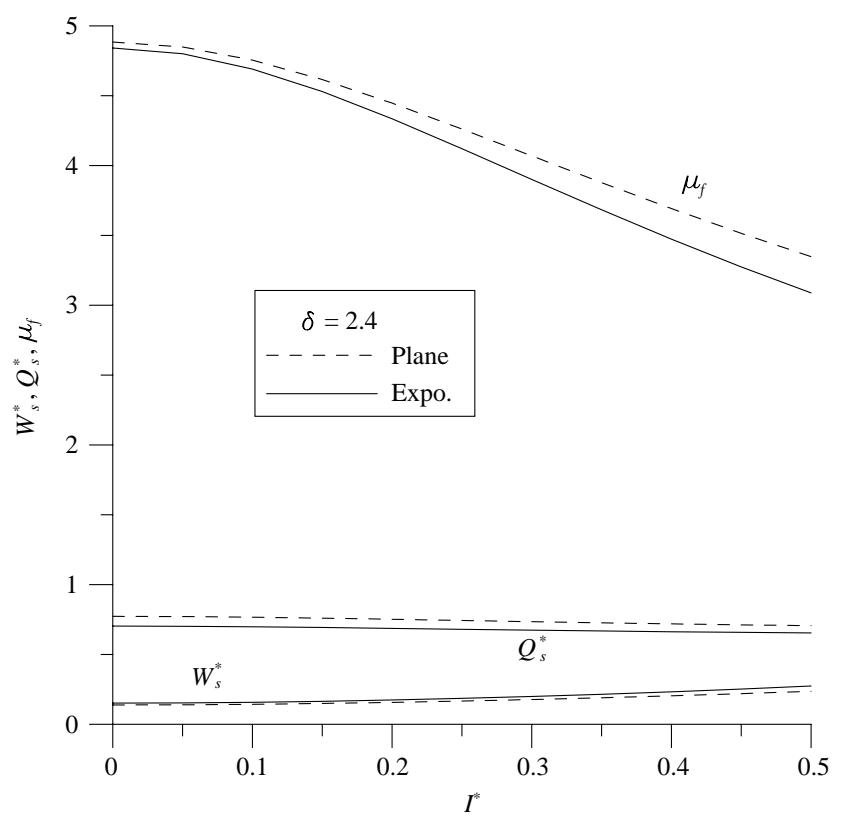

Fig. 8. Comparison of steady characteristics of bearings with an inclined-plane film and an exponential-shape film. stress dynamic Reynolds-type equation and is applied to evaluate the bearing dynamics. According to the results discussed, conclusions can be drawn as follows.

1. A closed-form solution for the hydrodynamic film force of the exponential shaped slider lubricated with couple stress fluids is derived and can be applied to predict bearing dynamics.

2. The effects of the bearing geometry (inclined-plane vs. exponential-shape) with smaller profile parameters has slight influence upon the load capacity, the friction parameter, the temperature rising and the volume flow rate. Furthermore, the exponentialshape slider results in a smaller stiffness coefficient as compared to the inclined-plane slider designed at a small profile parameter.

3. The effects of non-Newtonian couple stress fluids characterized by the couple stress parameter signify a reduction in the friction parameter and the volume flow rate, as well as an increase in the load-carrying capacity, the temperature rising, the dynamic stiffness coefficient and the dynamic damping coefficient for both types of the bearings. Comparing with those of the inclined slider bearing, the exponential shaped slider designed at larger profile parameters provides smaller volume flow rate higher load-carrying capacity and better dynamic stiffness and damping characteristics for larger values of the profile parameter. These improvements of bearing dynamics are more pronounced with increasing values of the nonNewtonian couple stress parameter.

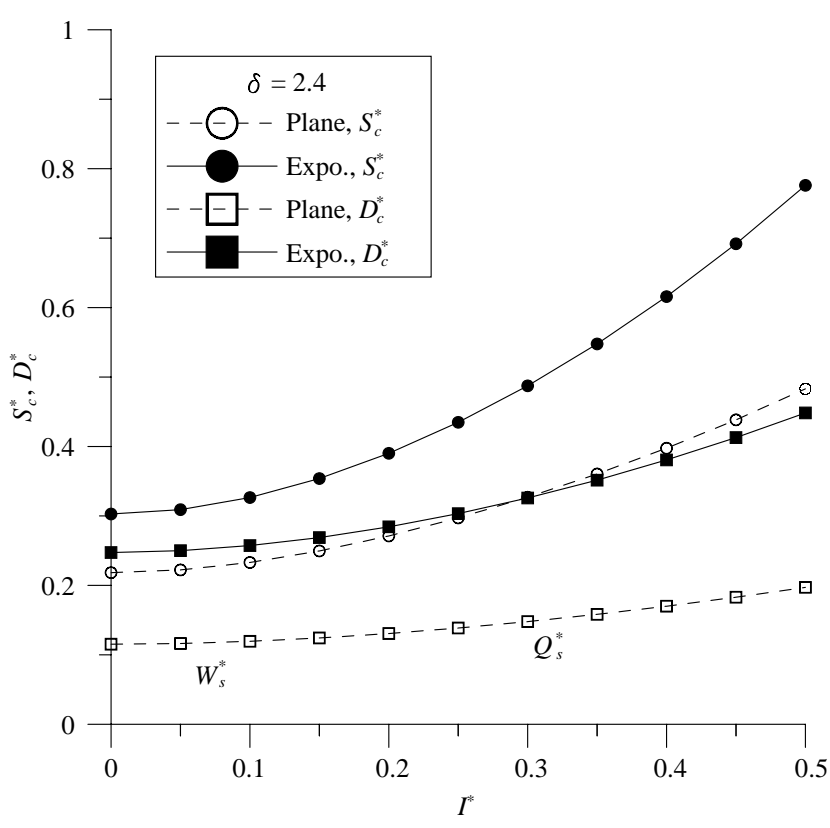

Fig. 9. Comparison of steady characteristics of bearings with an inclined-plane film and an exponential-shape film. 


\section{NOMENCLATURE}

$B, L \quad$ width and length of the bearing

$c_{1} \quad$ integration function, $c_{1}=c_{1}\left(h_{m}^{*}, V^{*}\right)$

$C_{p} \quad$ specific heat at constant pressure

$d \quad$ difference between the inlet and outlet film thickness

$D_{c}, D_{c}^{*} \quad$ damping coefficient, $D_{c}^{*}=D_{c} h_{m s}^{3} / \mu L^{3} B$

$F, F^{*} \quad$ hrdrodynamic film force, $F^{*}=F h_{m s}^{2} / \mu U L^{2} B=$ $F^{*}\left(h_{m}^{*}, V^{*}\right)$

$F_{L s}, F_{L s}^{*} \quad$ steady shearing force, $F_{L s}^{*}=F_{L s} h_{m s} / \mu U L B$

$g \quad$ gravitational acceleration

$h, h^{*} \quad$ film thickness, $h^{*}\left(x^{*}, t^{*}\right)=h(x, t) / h_{m s}$

$h_{e}^{*} \quad$ dimensionless exponential-film profile, $h_{e}^{*}(x)$ $=-\exp (-(x / L) \ln r)$

$h_{m}, h_{m}^{*} \quad$ minimum film thickness at the outlet, $h_{m}^{*}\left(t^{*}\right)=$ $h_{m}(t) / h_{m s}$

$h_{m s} \quad$ steady-state minimum film thickness at the outlet

$J \quad$ Joule's mechanical equivalent of heat

$l \quad$ characteristic length of the polar suspensions, $l=(\eta / \mu)^{1 / 2}$

$l^{*} \quad$ dimensionless couple stress parameter, $l^{*}=(l l$ $\left.h_{m s}\right)^{1 / 2}$

$p, p^{*} \quad$ hydrodynamic film pressure, $p^{*}=p h^{2}{ }_{m s} / \mu U L$

$q_{x}, Q_{s}^{*} \quad$ steady volume flow rate, $Q_{s}^{*}=q_{x} / U h_{m s} B$

$r \quad$ inlet-outlet film ratio, $r \cong\left(d+h_{m s}\right) / h_{m s}=\delta+$ 1

$S_{c}, S_{c}^{*} \quad$ stiffness coefficient, $S_{c}^{*}=S_{c} h_{m s}^{3} / \mu U L^{2} B$

$t, t^{*} \quad$ time, $t^{*}=U t / L$

$t_{m}, t_{m}^{*} \quad$ temperature rising, $t_{m}^{*}=J C_{p} \rho h_{m s}^{2} t_{m} / \mu U L$

$U \quad$ sliding velocity of the lower part

$u \quad$ velocity component in the $x$ direction

$V^{*} \quad$ dimensionless squeezing velocity, $V^{*}=d h_{m}^{*} I$ $d t^{*}$

$W_{s}, W_{s}^{*} \quad$ load-carrying capacity, $W_{s}^{*}=W_{s} h_{m s}^{2} / \mu U L^{2} B$

$x, z \quad$ Cartesian coordinates in the horizontal and vertical directions

$x^{*} \quad$ dimensionless coordinate, $x^{*}=x / L$

$\delta \quad$ dimensionless profile parameter, $\delta=d / h_{m s}$

$\eta \quad$ material constant responsible for a couple stress fluid

$\mu, \rho \quad$ lubricant viscosity and density

$\mu_{f} \quad$ dimensionless friction parameter, $\mu_{f}=-F_{L s} L /$ $W_{s} h_{m s}$

\section{Subscript}

$s \quad$ indicates the steady-state quantity

\section{REFERENCES}

1. Ariman, T. and Sylvester, N.D., "Microcontinuum Fluid Mechanics - A Review," International Journal of Engi- neering Science, Vol. 11, pp. $905-930$ (1973).

2. Ariman, T. and Sylvester, N.D., "Applications of Microcontinuum Fluid Mechanics," International Journal of Engineering Science, Vol. 12, pp. 273-293 (1974).

3. Bujurke, N.M. and Jayaraman, G., "The Influence of Couple Stresses in Squeeze Films," International Journal of Mechanical Science, Vol. 24, pp. 369-376 (1982).

4. Bujurke, N.M. and Naduvinami, N.G., "The Lubrication of Lightly Cylinders in Combined Rolling, Sliding and Normal Motion with Couple Stress Fluid," International Journal of Mechanical Science, Vol. 32, pp. 969-979 (1990).

5. Cameron, A., The Principles of Lubrication, Longmans Green \& Co Ltd, London (1966).

6. Das, D.C., "Elastohydrodynamic Lubrication Theory of Line Contacts: Couple Stress Fluid Model," Tribology Transctions, Vol. 40, pp. 353-359 (1997).

7. Gupta, R.S. and Sharma, L.G., "Analysis of Couple Stress Lubricant in Hydrostatic Thrust Bearings," Wear, Vol. 48, pp. 257-269 (1988).

8. Hamrock, B.J., Fundamentals of Fluid Film Lubrication, McGraw-Hill, Inc., New York (1994).

9. King, K.F. and Taylor, C.M., "An Estimation of the Effect Fluid Inertia on the Performance of the Plane Inclined Slider Thrust Bearing with Particular Regard to Turbulent Lubrication," ASME Journal of Lubrication Technology, Vol. 99, pp. 129-135 (1997).

10. Launder, B.E. and Leschziner, M.L., "Flow in Finitewidth, Thrust Bearings Including Inertia Effects," ASME Journal of Lubrication Technology, Vol. 100, pp. 330338 (1987).

11. Lin, J.R., "Couple-Stress Effects on the Squeeze Film Characteristics of Hemispherical Bearings with Reference to Synovial Joints," International Journal of Applied Mechanics and Engineering, Vol. 1, pp. 317-332 (1996).

12. Lin, J.R., "Effects of Couple Stresses on the Lubrication of Finite Journal Bearing," Wear, Vol. 206, pp. 171-178 (1997).

13. Lin, J.R., "Static and Dynamic Behavior of Externally Pressurized Circular Step Thrust Bearings Lubricated with Couple Stress Fluids," Tribology International, Vol. 32, pp. 207-216 (1999).

14. Lin, J.R., "Squeeze Film Characteristics Between a Sphere and a Flat Plate: Couple Stress Fluid Model," Computers \& Structures, Vol. 75, pp. 73-80 (2000).

15. Lin, J.R., "Linear Stability Analysis of Rotor Bearing System: Couple Stress Fluid Model," Computers \& Structures, Vol. 79, pp. 801-809 (2001).

16. Lin, J.R., Lu, R.F., and Chang, T.B., "Derivation of Dynamic Couple-Stress Reynolds Equation of Slidingsqueezing Surfaces and Numerical Solution of Plane Inclined Slider Bearings," Tribology International, Vol. 36, pp. 679-685 (2003). 
17. Lin, J.R., Lu, R.F., and Yang, C.B., "Linear Stability Analysis of a Wide Inclined Plane Slider Bearing," Journal of Science and Technology, Vol. 10, pp. 349-54 (2001).

18. Lin, J.R. and Hung, C.R., "Analysis of Dynamic Characteristics for Wide Slider Bearings with an Exponential Film Profile," Journal of Marine Science and Technology, Vol. 12, pp. 217-221 (2004).

19. Mokhiamer, U.M., Crosby, W.A., and El-Gamal, H.A., "A Study of a Journal Bearing Lubricated by Fluids with Couple Stress Considering the Elasticity of the Linear," Wear, Vol. 224, pp. 191-201 (1999).

20. Pinkus, O. and Sternlicht, B., Theory of Hydrodynamic Lubrication, McGraw-Hill, New York (1961).

21. Qvale, E.B. and Wiltshire, F.R., "The Performance of Hydrodynamic Lubricating Films with Viscosity Variations Perpendicular to the Direction of Motion," ASME Journal of Lubrication Technology, Vol. 94, pp. 44-48 (1972).

22. Ramanaish, G., "Squeeze Films Between Finite Plates Lubricated by Fluids with Couple Stress," Wear, Vol.
48, pp. 309-316 (1978).

23. Ramanaish, G., "Slider Bearings Lubricated by Fluids with Couple Stress," Wear, Vol. 52, pp. 27-36 (1979).

24. Rodkiewicz, C.M. and Anwar, M.I., "Inertia and Convective Effect in Hydrodynamic Lubrication of a Slider Bearing," ASME Journal of Lubrication Technology, Vol. 93, pp. 313-315 (1971).

25. Shehawey, E.F.Ei. and Mekheimer, Kh.S., "Couplestresses in Peristaltic Transport of Fluids," Journal of Physics D: Applied Physics, Vol. 27, pp. 1163-1170 (1994).

26. Srivastava, L.M., "Peristaltic Transport of a Couplestress Fluid," Rheology Acta, Vol. 25, pp. 638-641 (1986).

27. Stokes, V.K., "Couple Stresses in Fluids," Physics of Fluids, Vol. 9, pp. 1709-1715 (1966).

28. Talmage, G. and Carpino, M., "A Pseudospectral-finite Difference Analysis of an Infinitely Wide Slider Bearing with Thermal and Inertia Effects," STLE Tribology Transactions, Vol. 40, pp. 251-258 (1997). 